\title{
Effect of Ethanol on Grape Seed Proanthocyanidin Extraction
}

\author{
Alberto Hernández-Jiménez, ${ }^{1}$ James A. Kennedy, ${ }^{2}$ Ana B. Bautista-Ortín, ${ }^{1}$ \\ and Encarna Gómez-Plaza ${ }^{1 *}$
}

\begin{abstract}
Proanthocyanidins are found in the seeds and skins of winegrapes and are extracted into the must-wine during maceration. For seed proanthocyanidins, extraction is generally thought to be possible only in the presence of ethanol. This study examined the extraction of seed proanthocyanidins in model solutions with increasing concentrations of ethanol, from 0 to $15 \% \mathrm{v} / \mathrm{v}$. Spectrophotometric and chromatographic results showed that ethanol was not required for proanthocyanidin extraction, although its presence increased the rate of extraction. Extraction dynamics indicated that alcohol increased the rate of proanthocyanidin extraction for the initial six days of maceration, after which, even in the absence of ethanol, the extraction rate was nearly identical for all treatments. These findings suggest that extraction time is an important consideration when managing techniques, such as cold soak, which are thought not to affect seed proanthocyanidin extraction.
\end{abstract}

Key words: grape, seed, tannins, wine, proanthocyanidin, maceration, extraction

Tannins play an important role in red wine quality since they are responsible for astringency and bitterness mouthfeel properties. Grape tannins are proanthocyanidins, which are found in skin and seed tissue. In skin, they are mainly located in the skin cell vacuoles, and in seed they are found in the epidermis, the outer integument, and the inner integument (Cadot et al. 2006). Seed proanthocyanidins contain no prodelphinidins (Cortell et al. 2005) and a higher proportion of galloylated procyanidins (Labarbe et al. 1999, Prieur et al. $1994)$ and the mean degree of polymerization (mDP) is lower than skin proanthocyanidins (Cheynier et al. 1997, Moutounet et al. 1996).

Skin proanthocyanidins have frequently been described as "soft" or "ripe," contrary to seed proanthocyanidins, which have been associated with more aggressive and less desirable sensory descriptors like "green" or "hard." Studies have shown that the $\mathrm{mDP}$ and galloylation of wine proanthocyanidins are important structural variables that affect wine astringency perception. The percentage of galloylation has been positively correlated with astringency, and a strong positive correlation has been found between $\mathrm{mDP}$ and astringency (Vidal et al. 2003). However, Chira et al. (2009) found that the correlation between $\mathrm{mDP}$ and astringency could be modulated by the presence of epigallocatechin, so that skin proanthocyanidins provide a softer sensation than seed proanthocyanidins.

\footnotetext{
${ }^{1}$ Departamento de Tecnología de Alimentos, Nutrición y Bromatología. Facultad de Veterinaria, Universidad de Murcia, Campus de Espinardo, 30071 Murcia, Spain; and ${ }^{2}$ Department of Viticulture and Enology, California State University, 2360 East Barstow Avenue, MS VR89 Fresno, CA 93740.

*Corresponding author (email: encarnag@um.es)

Acknowledgments: This work was made possible by financial assistance of the Ministerio de Ciencia e Innovación, Project AGL2009-12503.

Manuscript submitted Jun 2011, revised Sept 2011, accepted Oct 2011

Copyright (C) 2012 by the American Society for Enology and Viticulture. All rights reserved.

doi: 10.5344/ajev.2011.11053
}

During maceration, proanthocyanidins are extracted from skin and seeds. In general, skin proanthocyanidins have been reported as being more readily extractible, whereas extraction from seeds requires longer maceration and is favored by the presence of ethanol (Canals et al. 2005, Llaudy et al. 2008, Gonzalez-Manzano et al. 2004). Wine proanthocyanidins can be manipulated by winemaking practices (Lee et al. 2008), with several of these practices based on the assumption that ethanol from fermentation is necessary to disorganize the outer lipidic layer that covers and isolates the seeds, meaning that seed proanthocyanidins are extracted at the end of alcoholic fermentation (Ribéreau-Gayon et al. 1998). In this way, short maceration periods have been used when wines with a high concentration of skin proanthocyanidins are desired, since most of the extraction occurred at low alcohol concentrations. Low temperature prefermentative macerations are also designed to increase the extraction and stabilization of the polyphenolic compounds (anthocyanins and proanthocyanidins) from skins during this prefermentative phase, avoiding the extraction of the more aggressive seed proanthocyanidins. However, in 1964 researchers demonstrated that water alone could extract an important amount of seed extractable polyphenols (Singleton and Draper 1964).

In this study, we used a model solution to determine how ethanol and time affect the amount and characteristics of proanthocyanidins extracted from seeds and to deepen our knowledge concerning the expected behavior of seed proanthocyanidins when using different techniques during winemaking.

\section{Materials and Methods}

Seeds from grapes of Vitis vinifera cv. Monastrell at commercial maturity (24.5 Brix) were extracted by hand, cleaned, and dried with cellulose paper, placed into hermetic bags filled with nitrogen and stored refrigerated at $4^{\circ} \mathrm{C}$ for a maximum of $24 \mathrm{hr}$ before maceration. Simulated maceration assays were performed at room temperature by placing $100 \mathrm{~g}$ seeds in $830 \mathrm{~mL}$ amber glass flasks filled (to the top) with model wine 
solutions (adjusted to $\mathrm{pH} 3.6$ with tartaric acid and $50 \mathrm{mg} / \mathrm{L}$ $\left.\mathrm{SO}_{2}\right)$ with increasing concentrations $(0,5,10$, and $15 \% \mathrm{v} / \mathrm{v})$ ethanol in triplicate. Each flask was vigorously shaken twice a day and sampled every two days (refilling with the original model solution, sparging with nitrogen to avoid oxidation) for up to 10 days. All assays were conducted in triplicate.

The absorbance measurements to determine total phenolic index were directly made in an extract after filtering and diluting 100-fold in a Helios Alpha spectrophotometer (Thermo Spectronic, Waltham, MA) with $1 \mathrm{~cm}$ path-length glass cells. Proanthocyanidin determination was carried out according to the method described by Kennedy and Jones (2001) with some modifications. To this end, $10 \mathrm{~mL}$ extract was concentrated under reduced pressure at $50^{\circ} \mathrm{C}$ and then redissolved in methanol in a volumetric flask. Then $100 \mu \mathrm{L}$ methanolic extract was reacted with $100 \mu \mathrm{L}$ phloroglucinolysis reagent (a solution of $0.2 \mathrm{~N} \mathrm{HCl}$ in methanol, containing $100 \mathrm{~g} / \mathrm{L}$ phloroglucinol and $20 \mathrm{~g} / \mathrm{L}$ ascorbic acid) in a water bath for 20 min at $50^{\circ} \mathrm{C}$ and then combined with 2 vol $200 \mathrm{mM}$ aqueous sodium acetate to stop the reaction. The flavan-3-ol monomer content present in the extract was measured, exchanging the phloroglucinolysis reagent for methanol.

HPLC analysis of proanthocyanidins followed the conditions described previously (Kennedy and Taylor 2003). The HPLC apparatus was a Waters 2695 system (Waters, Milford, MA) equipped with an autosampler and a Waters 2996 photodiode array detector. Samples $(10 \mu \mathrm{L}$ injection volume) were injected on two Chromolith RP-18e (100 x $4.6 \mathrm{~mm}, 5$ $\mu \mathrm{m}$ packing) columns connected in series and protected by a guard column (Purospher STAR RP-18e, 4 x 4 mm, $5 \mu \mathrm{m}$ packing), all of them from Merck (Darmstadt, Germany). The elution conditions were as follows: $3 \mathrm{~mL} / \mathrm{min}$ flow rate; oven temperature, $30^{\circ} \mathrm{C}$; solvent $\mathrm{A}$, water/acetic acid (99:1, $\mathrm{v} / \mathrm{v})$; and solvent B, acetonitrile/acetic acid (99:1 v/v). Eluting peaks were monitored at $280 \mathrm{~nm}$ and the elution began with $3 \% \mathrm{~B}$ for $4 \mathrm{~min}$, a linear gradient from 3 to $18 \% \mathrm{~B}$ in $10 \mathrm{~min}$, followed by washing and reequilibration of the column. Proanthocyanidin cleavage products were estimated using their response factors relative to $(+)$-catechin, which was used as the quantitative standard. These analyses allowed determination of the total proanthocyanidin content, the apparent $\mathrm{mDP}$, and the percentage of each constitutive unit. The mDP was calculated as the sum of all subunits (flavan-3-ol monomer and phloroglucinol adducts, in moles) divided by the sum of all flavan-3-ol monomers (in moles).

Statistical analyses. Significant differences in the proanthocyanidin concentration and composition for each variable at the different extraction times and for the different ethanol contents were assessed by multivariate analysis of variance (MANOVA). The LSD test was used to separate the means $(p<0.05)$ using the statistical package StatGraphics 5.0 Plus (StatPoint Technologies, Warrenton, VA).

\section{Results and Discussion}

The evolution over 10 days of tannin concentration in the model solutions differing in ethanol concentration is shown (Figure 1). Results show that ethanol is not necessary to release seed tannins since, after 10 days, a substantial proanthocyanidin concentration existed in the solution containing $0 \%$ ethanol, representing $72.60 \%$ of the maximum obtained in the solution containing $15 \%$ alcohol. The 5 and $10 \%$ ethanol concentrations showed intermediate values. These results are similar to those found for extractable seed phenols (Singleton and Draper 1964). From a practical point of view, these same authors also demonstrated that the same behavior was observed regardless of the temperature of extraction, the only difference being the amount of seed phenols extracted, which was $30 \%$ lower at $11.2^{\circ} \mathrm{C}$ than at $30^{\circ} \mathrm{C}$. These findings indicate that a considerable amount of seed proanthocyanidins would be extracted when performing prefermentative macerations during winemaking.

Two different zones can be observed in the plot representing tannin evolution in the different model solutions. From day 0 to day 6 , all evolutions can be fitted to a sigmoidal plot, the regression coefficients $\left(\mathrm{r}^{2}\right)$ ranking from 0.99 (for the $15 \%$ ethanol plot) to 0.82 (for the $0 \%$ ethanol plot). From day 6 to 10 , the plots can be perfectly fitted to a linear equation $(y=a x$ + b) with a very high $\mathrm{r}^{2}$ (the lowest at 0.98 for the $0 \%$ ethanol plot), showing an almost identical slope.

According to Cerpa-Calderón and Kennedy (2008), the general extraction of skin proanthocyanidins is consistent with the Boltzmann sigmoid equation:

$$
\mathrm{f}=\frac{\text { plateau concentration }}{1+\mathrm{e}^{-((\mathrm{x}-\mathrm{t} 50) / \text { slope })}}
$$

However, according the authors, it was uncertain if the Boltzmann sigmoid model would fit seed proanthocyanidin extraction, as seed proanthocyanidin extraction did not reach a plateau during the study period (Cerpa-Calderón and Kennedy 2008). Reflecting those results, we observed that the data from the first six days fit the Boltzmann equation but then, as the rate of extraction increased again, it did so linearly.

Adapting the interpretation of the given model (CerpaCalderón and Kennedy 2008) and for the first six days, the

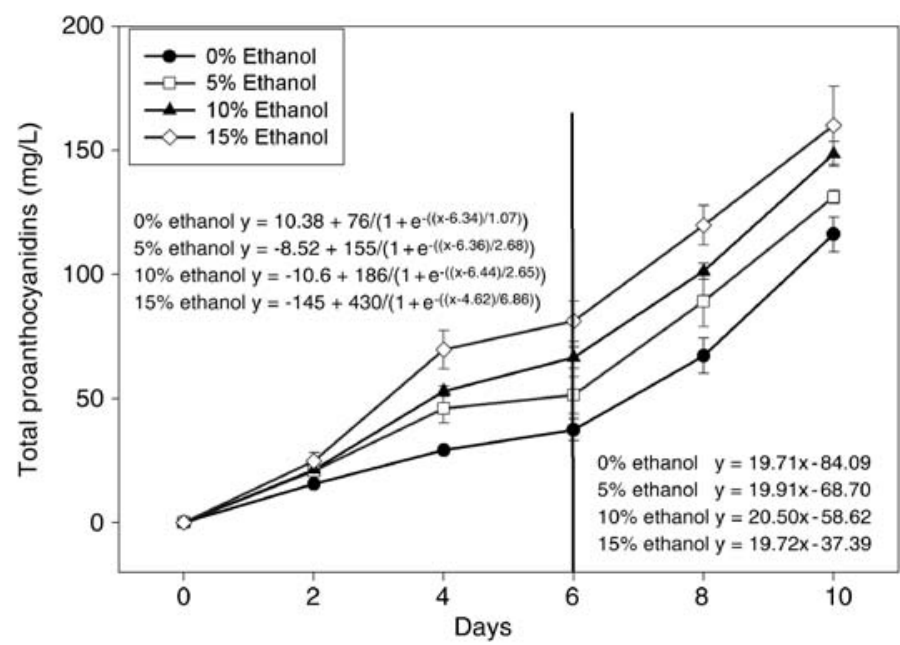

Figure 1 Total proanthocyanidin concentration in samples collected during maceration. Data expressed as means $(n=3 \pm$ SEM). 
initially slow extraction represents the period of time required for the proanthocyanidins to diffuse out of the plant cell and into the solution. After this time, the extraction was more pronounced. Singleton and Draper (1964) also described a lag period before the phenolic substances were extracted at a maximum rate. As ethanol content increases, so does the rate of maximum extraction. Finally, a small concentration plateau was reached, the value of which increased with ethanol content. One explanation for the observed concentration increase with ethanol is that ethanol leads to acceleration in the degradation of the outer protective layer of seeds.

From day 6 to day 10, proanthocyanidin extraction followed a linear equation. Interestingly, the slope of the individual equations was nearly the same at all ethanol concentrations, which could indicate that not only an effect of ethanol but also an effect of time was significant. Over time, seed cells may become increasingly hydrated and leaky and, when they reached a certain hydration level, proanthocyani- din extraction rate becomes constant and does not depend on ethanol concentration. Therefore, prior to day 6 there is an ethanol effect; after day 6 the ethanol effect is absent.

A two-way analysis of variance was also used to study the effect of ethanol and time of extraction on the proanthocyanidin composition of the different model solutions (Table 1, Table 2). As previously described, total phenols (OD280) and total proanthocyanidins increased with maceration time. The composition and characteristics of the extracted proanthocyanidins were similar to those reported by Prieur et al. (1994) for the second of five seed proanthocyanidin fractions obtained by preparative chromatography after extraction with acetone (fraction IIa). The findings of these authors suggest that only a fraction of the total bulk of seed proanthocyanidins was extracted under hydroalcoholic conditions, the others remaining unextracted. Singleton and Draper (1964) estimated that less than half of the seed proanthocyanidins would be extracted under typical winemaking conditions, and, in this way,

Table 1 Multivariate analysis of variance of the optical density at $280 \mathrm{~nm}$ (OD280), the mean degree of polymerization (mDP), and the concentration of monomeric and polymeric proanthocyanidins $(\mathrm{mg} / \mathrm{L})$ in the different model solution as affected by maceration time and alcohol content.

\begin{tabular}{|c|c|c|c|c|c|c|c|c|c|c|c|}
\hline & OD280 & mDP & $\begin{array}{l}\text { Monomeric } \\
\text { catechin }\end{array}$ & $\begin{array}{l}\text { Monomeric } \\
\text { epicatechin }\end{array}$ & tC & tEC & tECG & extc & extEC & extECG & Total \\
\hline \multicolumn{12}{|c|}{ Days } \\
\hline 2 & $1.39 \mathrm{a}^{\mathrm{a}}$ & $5.37 \mathrm{~b}$ & $2.28 a$ & $3.17 a$ & $1.71 \mathrm{a}$ & $1.18 a$ & $1.00 \mathrm{a}$ & $2.22 \mathrm{a}$ & $8.16 \mathrm{a}$ & $0.93 a$ & $20.67 a$ \\
\hline 4 & $2.28 b$ & $4.22 a$ & $4.18 b$ & $6.22 b$ & $5.13 b$ & $3.80 \mathrm{~b}$ & $2.17 \mathrm{~b}$ & $5.11 \mathrm{~b}$ & $20.69 b$ & $2.17 \mathrm{~b}$ & $49.46 b$ \\
\hline 6 & $2.99 c$ & $4.06 a$ & $5.41 \mathrm{c}$ & $6.83 b$ & $6.97 c$ & $4.55 b$ & $2.71 b$ & $5.70 \mathrm{~b}$ & $24.41 c$ & $2.54 b$ & $59.13 c$ \\
\hline 8 & $4.06 d$ & $4.28 a$ & $7.99 d$ & $11.22 \mathrm{c}$ & $9.30 d$ & $7.97 c$ & $3.65 c$ & $8.75 c$ & $41.14 d$ & $4.37 c$ & $94.70 d$ \\
\hline 10 & $4.85 \mathrm{e}$ & $4.46 a$ & $11.02 \mathrm{e}$ & $15.89 d$ & $13.49 \mathrm{e}$ & $10.66 d$ & $5.08 d$ & $12.68 d$ & $62.95 \mathrm{e}$ & $7.21 \mathrm{~d}$ & $138.992 e$ \\
\hline \multicolumn{12}{|c|}{$\%$ Alcohol } \\
\hline 0 & $2.10 a$ & $4.43 a$ & $4.75 a$ & $7.04 a$ & $5.51 \mathrm{a}$ & $4.55 a$ & $1.21 \mathrm{a}$ & $5.29 a$ & $22.98 a$ & $1.82 a$ & $53.12 \mathrm{a}$ \\
\hline 5 & $2.76 \mathrm{~b}$ & $3.93 a$ & $6.18 b$ & $8.63 b$ & $6.99 b$ & $6.03 b$ & $2.00 \mathrm{~b}$ & $6.51 b$ & $28.85 b$ & $2.55 b$ & $67.74 b$ \\
\hline 10 & $3.52 \mathrm{c}$ & $4.33 a$ & $6.71 \mathrm{c}$ & $9.18 b c$ & $8.01 \mathrm{c}$ & $6.06 \mathrm{~b}$ & $3.31 \mathrm{c}$ & $7.22 \mathrm{c}$ & 33.80 & $3.81 \mathrm{c}$ & $78.10 \mathrm{c}$ \\
\hline 15 & $4.23 d$ & $5.22 b$ & $7.06 c$ & $9.82 \mathrm{c}$ & $8.78 c$ & $5.87 \mathrm{~b}$ & $5.17 d$ & $8.55 d$ & $40.29 d$ & $5.60 d$ & $91.16 \mathrm{~d}$ \\
\hline
\end{tabular}

Abbreviations: mDP: mean degree of polymerization; tC: terminal (+)-catechin; tEC: terminal (-)-epicatechin; tECG: terminal (-)-epicatechin gallate; extC: extension (+)-catechin; extEC: extension (-)-epicatechin; extECG: extension (-)-epicatechin gallate.

aDifferent letters within the same column indicate significant differences $(p<0.05)$.

Table 2 Multivariate analysis of variance of the percentage (all values reported in \%) of the different monomeric and polymeric proanthocyanidins in the model solution as affected by maceration time and alcohol content.

\begin{tabular}{|c|c|c|c|c|c|c|c|c|c|c|c|c|}
\hline & $\begin{array}{l}\text { Monomeric } \\
\text { catechin }\end{array}$ & $\begin{array}{l}\text { Monomeric } \\
\text { epicatechin }\end{array}$ & tC & tEC & tECG & extC & extEC & extECG & $\begin{array}{c}\text { Total } \\
\text { monomers }\end{array}$ & $\begin{array}{c}\text { Total } \\
\text { polymers }\end{array}$ & $\begin{array}{l}\text { Terminal } \\
\text { subunits }\end{array}$ & $\begin{array}{c}\text { Extension } \\
\text { subunits }\end{array}$ \\
\hline \multicolumn{13}{|c|}{ Days } \\
\hline 2 & $10.94 c^{a}$ & $15.36 \mathrm{c}$ & $8.39 a$ & $5.75 a$ & $4.73 b$ & $10.85 d$ & $39.51 a$ & 4.47ab & $26.29 \mathrm{c}$ & $73.71 \mathrm{a}$ & $18.87 a$ & $54.84 a$ \\
\hline 4 & $8.55 a$ & $12.85 b$ & $10.40 b$ & $7.75 b$ & 4.16ab & $10.40 c$ & $41.60 \mathrm{~b}$ & $4.29 a$ & $21.40 \mathrm{~b}$ & $78.60 \mathrm{~b}$ & $22.31 b c$ & $56.29 a b$ \\
\hline 6 & $9.38 b$ & $11.65 a$ & $11.79 c$ & $7.69 \mathrm{~b}$ & $4.26 a b$ & $9.78 b$ & $41.41 b$ & $4.05 a$ & $21.03 b$ & $78.97 b$ & $23.74 \mathrm{c}$ & $55.23 a$ \\
\hline 8 & $8.72 a$ & $11.88 \mathrm{a}$ & $9.84 b$ & $8.44 b$ & $3.72 a$ & $9.32 a$ & $43.79 c$ & $4.60 \mathrm{ab}$ & $20.30 a b$ & $79.70 \mathrm{bc}$ & $21.99 b$ & $57.71 b c$ \\
\hline 10 & $8.04 a$ & $11.67 \mathrm{a}$ & $9.76 \mathrm{~b}$ & $7.84 b$ & $3.47 a$ & $9.13 a$ & $45.10 \mathrm{~d}$ & $4.96 b$ & $19.71 \mathrm{a}$ & $80.29 c$ & $21.09 b$ & $59.2 c$ \\
\hline \multicolumn{13}{|c|}{$\%$ Alcohol } \\
\hline 0 & $9.05 b$ & $13.36 \mathrm{~b}$ & $10.33 b$ & $7.44 b$ & $2.89 a$ & $10.54 c$ & $42.61 b c$ & $3.79 a$ & $22.41 \mathrm{~b}$ & $77.59 a$ & $20.65 a$ & $56.94 b$ \\
\hline 5 & $9.61 b$ & 13.01b & 10.26 & $9.05 c$ & $3.01 \mathrm{a}$ & $9.89 \mathrm{~b}$ & $41.41 \mathrm{a}$ & $3.76 \mathrm{a}$ & $22.62 b$ & $77.38 a$ & $22.32 b$ & $55.06 a$ \\
\hline 10 & $9.28 b$ & $12.63 b$ & 10.12ab & $7.61 b c$ & $4.51 b$ & $9.48 a$ & $41.77 a b$ & $4.59 b$ & $21.91 b$ & $78.09 a$ & $22.25 b$ & $55.84 a b$ \\
\hline 15 & $8.33 a$ & $11.73 a$ & $9.45 a$ & $5.88 a$ & $5.85 c$ & $9.67 a b$ & $43.33 c$ & $5.76 c$ & $20.06 a$ & $79.94 b$ & $21.18 \mathrm{ab}$ & $58.76 \mathrm{c}$ \\
\hline
\end{tabular}

Abbreviations: tC: percentage of terminal (+)-catechin; tEC: percentage of terminal (-)-epicatechin; tECG: percentage of terminal (-)-epicatechin gallate; extC: percentage of extension (+)-catechin; extEC: percentage of extension (-)-epicatechin; extECG: percentage of extension (-)-epicatechin gallate.

${ }^{a}$ Different letters within the same column indicate significant differences $(p<0.05)$. 
a theoretical seed proanthocyanidin extraction of $9.2 \%, 7.2 \%$, and $8.7 \%$ was obtained in wines from Monastrell, Cabernet Sauvignon, and Syrah grapes, respectively (Busse-Valverde et al. 2010). Higher theoretical seed proanthocyanidin extraction was found from Merlot grapes (42\%) (Cerpa-Calderón and Kennedy 2008).

No increase in mDP was observed as maceration time increased, a result consistent with those reported elsewhere (Llaudy et al. 2008). The percentage of monomeric compounds (catechin and epicatechin) decreased with time (they are readily extracted at the beginning of the maceration process) and the percentage of polymeric proanthocyanidins increased. However, very small differences in terminal and extension subunit composition were observed during maceration.

When the effect of the ethanol content was observed, mDP changed little, only increasing significantly when the solution contained $15 \%$ ethanol, whereas an increase in OD280 (50\%) and total proanthocyanidins (40\%) was evident with increasing ethanol concentrations. Consistent with the increase in total proanthocyanidins, all the different fractions of monomer compounds and polymeric compounds increased. The percentage of monomeric compounds decreased as the alcohol content increased, whereas the percentage of polymeric proanthocyanidins increased; terminal epicatechin-3-O-gallate doubled its concentration and extension epicatechin-3-O-gallate increased its percentage, although to a lesser extent. Geny et al. (2003) found a higher proportion of epicatechin-3-O-gallate in the proanthocyanidins located in the seed cell wall fraction than in the inner part of the cell, so that a greater degradation of the cell walls with increasing alcohol content could promote a higher release of more galloylated proanthocyanidins. Similarly, Koyama et al. (2007) indicated that the galloylated proanthocyanidins, which present higher hydrophobicity, might be selectively trapped by internal components of the seed cells and be released with the aid of increased ethanol concentrations. This effect was also observed in wines, where the percentage of galloylation increased during the second part of fermentation, when alcohol reached high values (BusseValverde et al. 2011), which may be of sensory importance since astringency increases with galloylation (Vidal et al. 2003). Overall, the percentage of terminal and extension subunits changed little.

\section{Conclusions}

Results indicate that ethanol is not essential for the extraction of seed tannins, although their extraction is more intense and faster when ethanol is present, especially at the beginning of the maceration period, since from day 6 to 10 the rate of extraction was similar for all solutions. The main effect of ethanol is probably to help disorganize the outer lipidic layer that protects seeds. However, time also has an important role, increasing seed cells hydration and leakiness. It appears that, once a certain level of seed cell hydration is reached, tannins are extracted independently of alcohol content. The mDP did not change with longer maceration times and very little with increasing ethanol content, probably because only a small fraction of the total seed tannin content is extracted in hydroalcoholic solutions. The proportion of galloylated proanthocyanidin did not increase with maceration time but almost doubled its value as the alcohol content increased, probably due to the different binding and localization these more complex molecules could have on the seed.

From a practical point of view and considering 10 days as a usual prefermentative maceration time in techniques such as prefermentative cold soak, the diffusion kinetics found in this research will be of interest to winemakers. Prefermentative maceration not only would extract a considerable amount of seed tannins but also, in some way, would prepare seeds for a linear extraction during fermentative maceration. These results confirm those obtained by Alvarez et al. (2005) and Busse-Valverde et al. (2010, 2011), who found increased seed PA content and galloylation in wines after applying low temperature prefermentative macerations.

\section{Literature Cited}

Alvarez, I., J.L. Aleixandre, M.J. García, and V. Lizama. 2005. Impact of prefermentative maceration on the phenolic and volatile compounds in Monastrell red wines. Anal. Chim. Acta 23:109-115.

Busse-Valverde, N., E. Gómez-Plaza, J.M. López-Roca, R. Gil-Muñoz, J.I. Fernández-Fernández, and A.B. Bautista-Ortín. 2010. Effect of different enological practices on skin and seed proanthocyanidins in three varietal wines. J. Agric. Food Chem. 58:11333-11339.

Busse-Valverde, N., E. Gómez-Plaza, J.M. López-Roca, R. Gil-Muñoz, and A.B. Bautista-Ortín. 2011. The extraction of anthocyanins and proanthocyanins from grapes to wine during fermentative maceration is affected by the enological technique. J. Agric. Food Chem. 59:5450-5455.

Cadot, Y., M.T. Minana-Castello, and M. Chevalier. 2006. Anatomical, histological, and histochemical changes in grape seeds from Vitis vinifera L. cv. Cabernet franc during fruit development. J. Agric. Food Chem. 54:9206-9215.

Canals, R., M.C. Llaudy, J. Valls, J.M. Canals, and F. Zamora. 2005. Influence of ethanol concentration on the extraction of color and phenolic compounds from the skin and seeds of Tempranillo grapes at different stages of ripening. J. Agric. Food Chem. 53:4019-4025.

Cerpa-Calderón, F.K., and J.A. Kennedy. 2008. Berry integrity and extraction of skin and seed proanthocyanidins during red wine fermentation. J. Agric. Food Chem. 56:9006-9014.

Cheynier, V., C. Prieur, S. Guyot, J. Rigaud, and M. Moutounet. 1997. The structures of tannins in grapes and wines and their interaction with proteins. In Wine: Nutritional and Therapeutic Benefits. T.R. Watkins (ed.), pp. 81-93. Am. Chemical Society, Washington, DC.

Chira, K., G. Schmauch, C. Saucier, S. Fabre, and P.L. Teissedre. 2009. Grape variety effect on proanthocyanidin composition and sensory perception of skin and seed tannin extracts from Bordeaux wine grapes (Cabernet Sauvignon and Merlot) for two consecutive vintages (2006 and 2007). J. Agric. Food Chem. 57:545-553.

Cortell, J.M., M. Halbleib, A.V. Gallagher, T.L. Righetti, and J.A. Kennedy. 2005. Influence of vine vigor on grape (Vitis vinifera L. cv. Pinot noir) and wine proanthocyanidins. J. Agric. Food Chem. 53:5798-5808.

Geny, L., C. Saucier, S. Bracco, F. Daviaud, and Y. Glories. 2003. Composition and cellular localization of tannins in grape seeds during maturation. J. Agric. Food Chem. 51:8051-8054.

Gonzalez-Manzano, S., C. Rivas-Gonzalo, and C. Santos-Buelga. 2004. Extraction of flavan-3-ols from grape seed and skin into wine using simulated maceration. Anal. Chim. Acta 513:283-289. 
Kennedy, J.A., and G.P. Jones. 2001. Analysis of proanthocyanidin cleavage products following acid-catalysis in the presence of excess phloroglucinol. J. Agric. Food Chem. 49:1740-1746.

Kennedy, J.A., and A.W. Taylor. 2003. Analysis of proanthocyanidins by high-performance gel permeation chromatography. J. Chromatogr., A 995:99-107.

Koyama, K., N. Goto-Yamamoto, and K. Hashizume. 2007. Influence of maceration temperature in red wine vinification on extraction of phenolics from berry skins and seeds of grape (Vitis vinifera). Biosci. Biotechnol. Biochem. 71:958-965.

Labarbe, B., F.V. Cheynier, F. Brossand, J. Souquet, and M. Moutounet. 1999. Quantitative fractionation of grape proanthocyanidins according to their degree of polymerization. J. Agric. Food Chem. 47:2719-2723.

Lee, J., J.A. Kennedy, C. Devlin, M. Redhead, and C. Rennaker. 2008. Effect of early seed removal during fermentation on proanthocyanidin extraction in red wine: A commercial production example. Food Chem. 107:1270-1273.

Llaudy, M.C., R. Canals, J.M. Canals, and F. Zamora. 2008. Influence of ripening stage and maceration length on the contribution of grape skins, seeds, and stems to phenolic composition and astringency in wine-simulated macerations. Eur. Food Res. Technol. 226:337-344.

Moutounet, M., J. Rigaud, J.M. Souquet, and V. Cheynier. 1996. Caracterisation structurale des tanins de las baie de raisin. Quelques exemples de l'incidence du cepage, du terroir et du monde de conduite de la vigne (1). Bull. OIV 783-784:433-443.

Prieur, C., J. Rigaud, V. Cheynier, and M. Moutounet. 1994. Oligomeric and polymeric procyanidins from grape seeds. Phytochemistry 36:781-784.

Ribéreau-Gayon, P., D. Dubourdieu, B. Donèche, and A. Lonvaud. 1998. Traité d' Oenologie. 1. Microbiologie du vin. Vinifications. Ed. Dunod, Paris.

Singleton, V.L., and D.E. Draper. 1964. The transfer of polyphenolic compounds from grape seeds into wines. Am. J. Enol. Vitic. 15:34-40.

Vidal, S., I.L. Francis, S. Guyot, N. Mamet, M. Kwiatkowski, R. Gawel, V. Cheynier, and E. Waters. 2003. The mouth-feel properties of grape and apple proanthocyanidins in a wine-like medium. J. Sci. Food Agric. 83:564-573. 